- Many dental schools in the UK are expanding their outreach teaching.

- This paper looks at outreach as a context for teaching undergraduate restorative dentistry.

- A three year pilot study indicated that outreach is a more demanding environment for teaching than the dental hospital.

- Staff selection, training and ongoing support are key factors.

- Management and teaching transfers from the dental school to the PCT and the educational and organisational implications need to be monitored.

\title{
The use of outreach clinics for teaching undergraduate restorative dentistry
}

\author{
A. Elkind, ${ }_{1}^{1}$ C. Watts, ${ }^{2}$ A. Qualtrough, ${ }^{3}$ A. S. Blinkhorn ${ }_{1}^{4}$ C. Potter ${ }_{1}^{5}$ J. Duxbury, ${ }_{1}^{6}$ F. Blinkhorn, ${ }_{1}^{7}$ I. Taylor ${ }^{8}$ \\ and R. Turner ${ }^{9}$
}

\begin{abstract}
Aim To examine the experience of being an outreach teacher of undergraduate restorative dentistry; to describe the desirable characteristics of such teachers; and to consider the management of outreach teaching. Design A three year pilot of an outreach course in fourth year restorative dentistry began in 2001. Students spent one day per week treating adults in NHS community dental clinics, run by Primary Care Trusts (PCTs). Action research involved monitoring meetings with students, clinic staff (dental teachers and nurses), and PCT clinical service managers. These data are supplemented by an independent evaluation involving interviews with dental school academic staff, and an account by an outreach teacher. Results Outreach is a different and more demanding context for teaching restorative dentistry than the dental hospital, characterised by isolation, management responsibility, pressure, a steep learning curve, and stress. The desirable characteristics of outreach teachers are those which enable them to cope in this environment, together with a student-centred teaching style, and the appropriate knowledge. Management of teaching passed to the PCTs and this created an additional workload for them in relation to staffing, risk, and service-based issues. Four teaching surgeries were the maximum for a satisfactory level of patient care and student supervision. A key issue for the dental school is quality. The changes to teaching and the teaching environment introduced during and after the pilot to address problems identified are described. Conclusion In developing facilities to enable students to benefit from the advantages of outreach, dental schools should recognise that the characteristics of the outreach environment need to be taken into account during planning, that staff selection is a critical success factor, and that an ongoing proactive approach to organisational arrangements and to the support of teaching staff is necessary.
\end{abstract}

\footnotetext{
'Administrative Director of Dental Education in Primary Care, ${ }^{2}$ Senior Dental Officer, ${ }^{3}$ Senior Lecturer/Honorary Consultant in Restorative Dentistry, ${ }^{4 *}$ Professor of Oral Health, School of Dentistry, University of Manchester, Higher Cambridge Street, Manchester, M15 6FH; ${ }^{5}$ PDS Dentist/Honorary Clinical Tutor, Salford PCT, Dental Department, Ordsall Health Centre, Belfort Drive, Salford, M5 3PP; ${ }^{6}$ Consultant in Dental Public Health, Mauldeth House, Mauldeth Road West, Manchester, M21 7RL; ${ }^{7}$ Director of Dental Services, Salford PCT, Lance Burn Health Centre, Churchill Way, Salford, M6 5BN; ${ }^{8} \mathrm{Head}$ of Evaluation Unit, ${ }^{9}$ Research Evaluator, Liverpool Evaluation Unit, Student Services Centre, 150 Mount Pleasant, University of Liverpool, L69 3GD

*Correspondence to: Professor A. S. Blinkhorn

Email:anthony.blinkhorn@manchester.ac.uk
}

\section{Refereed Paper}

Accepted 12 October 2006

DOI: $10.1038 /$ bdj.2007.681

${ }^{\oplus}$ British Dental Journal 2007; 203: 127-132

\section{INTRODUCTION}

Options for change ${ }^{1}$ proposed that future dental education in England should focus on developing the skills needed in practice, with greater use of primary care outreach schemes throughout undergraduate training. The Chief Dental Officer is now funding consortia of dental schools to expand outreach teaching, to give undergraduates clinical experience in primary care settings. The School of Dentistry at the University of Manchester has provided outreach teaching in community clinics in deprived areas, in partnership with salaried dental services in Greater Manchester, for many years. The evaluation of the children's dentistry course, initiated in the 1970s, identified the importance of suitable staff. ${ }^{2}$

A strategy to develop dental education in primary care further in Manchester was initiated in the late 1990s. This aims to give students experience of providing comprehensive care for adults in a primary care setting. A three year pilot of an outreach course in restorative dentistry began in 2001. Its aims were to test the feasibility of this strategy by developing an outreach course for clinical 
training in fourth year undergraduate restorative dentistry in NHS community-based dental clinics, and to assess the organisational, service and educational implications. This paper looks at outreach as a context for teaching with particular reference to restorative dentistry, in terms of the experience of being an outreach teacher, the desirable characteristics of outreach teachers, and the management of outreach teaching.

Chapnick and Chapnick ${ }^{3}$ question the assumption that expert knowledge and technical skills are sufficient for successful dental teaching. It leads to a teacher-centred approach, with a focus on the teacher as a transmitter of information, which passes from the expert teacher to the novice learner. A studentcentred approach focuses on changes in students' learning and on what students do to achieve this. In the latter model the teacher's task is to engage students in learning and to motivate them. ${ }^{4}$ of the 12 roles identified for the medical teacher the most relevant for the dental clinical teacher are the clinical or practical teacher, the on-the-job-role model, the role model as teacher, the learning facilitator, and the student assessor. These are associated with a high level of face-to-face contact with students and tend to require content expertise and knowledge. ${ }^{4}$ In addition, clinical learning in restorative dentistry is centred on the provision of patient care. The clinical teacher must also be a clinical supervisor, and tension exists between the learning needs of the student and the need to prevent harm to the patient. ${ }^{5}$

Studies of dental clinical teaching have tended to focus on the dental hospital setting. Chambers, Geissenberger and Leknius ${ }^{6}$ identified four 'types' of effective instructor from dental faculty members' responses: expert, enthusiast, judicial, and good soldier. Those teachers who placed emphasis on expertise received lower ratings from students for teacher effectiveness. Those who saw their roles as motivating students, explaining difficult concepts, displaying interest in the subject, showing compassion and caring, and being proactive were rated highly for effectiveness. Specifically in relation to restorative dentistry, ${ }^{5}$ teacher characteristics identified as desirable by students included professional competence, approachable personality, punctuality, availability, consistency, practicality, understanding the limits of student knowledge, and respect for the student-patient relationship. Teaching/learning behaviours of importance were feedback, demonstration, integration of theory and practice, student autonomy, and self-assessment.

In the case of dental outreach teachers, their characteristics, skills and behaviours are deployed in a different clinical and organisational context. British dental schools have developed a variety of models of outreach. For example, the hub and spoke model has a small dental school as the hub and what are in effect mini-dental schools, sometimes in other towns, as the spokes. In the latter case students may attend for blocks of weeks at a time and live in the locality. In a second model the standard dental school has an off-site primary care clinic. Here students treat primary care patients, but in a setting that largely replicates the conditions of the main dental hospital in terms of physical layout, student teaching and supervision. The Manchester model, described here, is based on a standard dental school, where students attend regular sessions in small local NHS-run community dental clinics with individual surgeries, reproducing as far as possible the experience of primary care dental practice.

In organisational terms, the perceived advantages of outreach teaching for dental schools are enhancing links with the community - further developing partnership with the NHS, providing a wider pool of teachers and patients, and an opportunity for research. For the host organisation participation is perceived to offer improved staff motivation and recruitment, a link with an academic centre providing support for clinical governance, research and continuing professional development, plus the opportunity to develop local service provision. $^{7}$

\section{DESIGN}

Pilot outreach course in restorative dentistry

The pilot was run in partnership with the salaried dental services from Manchester Primary Care Trusts (PCT) and Salford PCT. The PCTs provided teaching facilities on two days per week at each of three community clinics in the first year, 2001/2, increasing to four clinics from 2002/3 onwards. Three clinics had hitherto provided a traditional community dental service for children and adults with special needs and had participated in the paediatric outreach teaching course. The fourth clinic was new and operated as a personal dental services pilot, offering a service to the full range of patients. The dental clinics each had four surgeries, with one exception where five surgeries were available on one day per week. All were in socially deprived areas with poor oral health, and inadequate access to general dental services.

Teaching and supervision were the responsibility of primary care practitioners, with support from dental nurses. The teachers were recruited and managed by the PCTs. One existing Senior Dental Officer who had experience both of teaching in outreach and of general practice was transferred to the pilot. However the teaching skills of other salaried PCT dental staff were mainly in relation to paediatric dentistry. Therefore two dentists with experience of general practice and with an interest in teaching students were specifically recruited for the pilot. A fourth post was created in the second year of the pilot and filled by two primary care practitioners. Two of the original outreach teachers remained in post throughout the three years of the pilot. At other clinics personnel changes occurred for a variety of reasons, so that a total of nine dentists taught the course at some stage. Some worked full-time in salaried dental services; others combined the appointment with their own general dental practice. Previous experience of teaching varied. All appointments were with the approval of the dental school. Some of the new recruits had a period of training at the dental hospital to enable consistency of approach, but the extent of this depended on the date of appointment.

Prior to the pilot, fourth year restorative dentistry was taught in five clinical sessions per week in three specialist clinics: operative dentistry and endodontics, prosthodontics and periodontics. For the new course two of these sessions were transferred to the community dental clinics so that each fourth year student spent one day per week in restorative outreach for the academic year. Groups of eight or 10 worked in pairs to provide a holistic dental service to adult patients, supported by dental nurses. Students also attended seminars. After each 
clinical session students were assessed using a standard dental school protocol. The educational aims and objectives of the outreach course emphasised integrated patient care, treatment planning, confidence, communication, referrals, and effective use of time and resources.

\section{EVALUATION}

The evaluation of the pilot as a whole was multifaceted, using a range of techniques. Ovretveit ${ }^{8}$ defines evaluation as a judgement of the value of an intervention as a basis for informed decision-making. Findings about student opinion of outreach, the patientbase, and service quality implications for PCTs based on the use of records and questionnaires, have been reported elsewhere. ${ }^{9-11}$ Here the focus is on exploring issues around outreach as a context for teaching, based mainly on the results of action research. This is interventionist in character, the researcher both identifying problems and participating in decisions about what is to be done. The process involves collecting data about an ongoing system, feeding the data back into the system, taking action, and assessing the results of the action by collecting more data. ${ }^{12}$ Action evaluation is formative in character and aims to change the intervention while evaluating it. ${ }^{8}$ The method is also a means of programme development, involving key players in the process, ${ }^{13}$ and being qualitative is concerned to develop an understanding of the perceptions and interpretations of those involved..$^{14}$

The project manager held monitoring meetings twice a year with the dental teachers and dental nurses (usually the senior nurse) who staffed the outreach clinics, and with representatives of the students at each clinic. Monitoring meetings were also held with the PCT Clinical Directors, who managed the service. The meetings took the form of semi-structured interviews with individuals or groups, whose comments were recorded on a proforma. The results were fed back to the Project Development Team via written reports and action identified. The Development Team members included key players in the dental school and the NHS, including the outreach teachers. The data were analysed to report progress, to identify themes, and to highlight problems. Review workshops were held at the end of each year to assess experience and identify changes for the following year. Less formally, activity outside this structured process also informed the development of understanding of issues about teaching in outreach.

During the first year the findings of the action research in relation to teaching were mainly concerned with the emerging perceptions of staff about the nature of teaching in outreach, and this continued to be a theme throughout the pilot. By the second year, the recruitment, selection and retention of teachers had become an issue, and the characteristics of outreach teachers were examined in the round of monitoring meetings held in June and July 2003. The clinic dentists, the senior dental nurses and the PCT Clinical Directors were asked what they considered to be the qualities and skills needed in a teacher in outreach. Students were not questioned directly about this, but were asked about the teaching and supervision they had received during the year. At the end of the second year, a third theme emerged in relation to the management of outreach teaching.

As well as the findings of the action research, other material is drawn upon here. An independent evaluation of the pilot as a whole consisted of semi-structured interviews held in May 2003 with the heads of unit in restorative dentistry ${ }^{15}$ and included findings related to the themes identified above. In addition, one of the original teachers provided an account of teaching on an outreach course in the report of the first year of the pilot. ${ }^{16}$

\section{RESULTS}

The experience of being an outreach teacher

Outreach represents a different and more demanding context for teaching restorative dentistry than the dental hospital. This can be characterised in terms of isolation, heavy responsibility, pressure, and a steep learning curve, which together produce a stressful working environment.

For new outreach teachers a steep learning curve was experienced as they developed their teaching and assessment skills, learnt how to run the clinic and to manage students, and adjusted to the organisational and educational problems involved in developing a new course. The result was a very high level of stress. As student skills improved over the year, and as the teachers gained in experience during the pilot and knew what to expect, the pressure decreased and the process became more enjoyable and rewarding. Nevertheless outreach remained a stressful working environment even for the experienced.

In the outreach clinic the teacher was usually the only dentist present. This meant that, unlike in the dental hospital, they did not have a support system of other professional colleagues to call on for clinical consultation or advice. Moreover if something went wrong, for example a student made a mistake or a patient was taken ill, they had to deal with this alone, and at the same time continue to supervise the other students. This sense of isolation was exacerbated when the outreach teachers did not feel supported or valued by the dental school. For example, where patients were referred for specialist advice, this was not always dealt with in a way the teacher found satisfactory. In general outreach teachers were considered to carry a heavier responsibility than their hospital-based colleagues, as they had to manage the clinic as well as teach the students. In addition the pace of work was faster, reflecting the reality of a service-oriented environment.

The students were considered by their teachers to be inadequately prepared for clinic life, for example in terms of cross infection control and basic skills such as writing up notes. Moreover the outreach teachers were generalists, but often had to deal with procedures that the student had not yet covered at the dental hospital, without being able to provide students with the specialist teaching they expected there. Students tended to be anxious about meeting their course requirements and this added to the pressure on clinic staff. The seminar programme was considered too academic, the teachers finding briefing and review sessions more helpful.

It remained the case throughout the pilot that the nurses tended to be dissatisfied with their role as a result of student pairing. They considered that both speed and cross-infection control would have been improved if they had provided one-to-one chairside assistance to students. 
Nevertheless, the clinic staff were positive about the benefits of outreach for students and highlighted key areas of student development as improved history taking and treatment planning; increased confidence; good relationships with patients; improved/good clinical skills; improved speed; reduced need for supervision; and improved relationships with nurses. From the point of view of the dental school academics the benefits of outreach teaching included increasing student capability in relation to confidence, communication, awareness of holistic care, and capacity to care for a range of patients needs. In addition outreach teaching provided a smoother transition to the fifth year and linked more effectively with postgraduate vocational training. The programme built a bridge between the dental school and community practice.

\section{Desirable characteristics of a teacher in outreach}

Table 1 summarises the characteristics that were identified as desirable for a teacher in outreach by the dentists themselves, the nurses, students, Clinical Directors, and dental school academics. The characteristics are not presented in any order of importance, and although each group had its own perspective, the method of data collection means that presenting these variations might be misleading. Looking at the findings overall, an important focus was on the personal qualities of the individual teacher, who has to find the right balance between openness and authority, while remaining calm and good humoured. The abilities identified were largely concerned with the capacity to work in the stressful environment that was described above, and balancing being in charge of the situation with the ability to let go enough to allow students to learn. The skills required were seen as managerial as well as clinical, together with a capacity to work appropriately with both nurses and patients. Teaching skills were specified in detail and focused on the development of a successful two-way relationship with students, based on mutual respect, support, flexibility, and clarity. The knowledge required was identified as that of the up-to-date generalist who is aware of academic standards.
The management of outreach teaching

From the PCT perspective the main advantages of providing teaching facilities were the development of an accessible service for patients, including an emergency service, and the contribution made to the PCT's role in teaching and learning. However in outreach, the management of teachers and the teaching environment passes from the dental school to the PCT, and this created an additional management workload for the PCT in terms of staff, risk, and service.

Staffing problems included the recruitment of appropriate staff, dealing with the personnel problems generated by staff in post, and dealing with staff stress caused by the issues described above. Managing part-time staff who worked on a sessional basis created particular difficulties in relation to areas such as training and clinical governance. In terms of risk management, PCTs were concerned with the health and safety implications of teaching, particularly cross infection control and patient injuries, and with the way students used materials and equipment. Although the overall responsibility for student behaviour and discipline was retained by the dental school, initially these matters had to be dealt with by the teacher at clinic level. PCTs also became responsible for dealing with patient complaints. At the service level, the main concerns were ensuring that meeting the educational needs of students was congruent with meeting the service needs of patients. PCTs had to develop techniques to manage patient demand and expectations, deal with patients when students were not present, and develop pathways for patients who were unsuitable for student treatment. Funding arrangements were also of concern.

Each pilot clinic had a different physical layout, but in all cases students worked in individual surgeries. The pilot began with four surgery clinics as this was what was available. However in the longer term the intention was to develop six surgery clinics, to reflect the dental school approach of organising students into groups of 12, working in six pairs of two. In the second year of the pilot a five surgery clinic was introduced. The feedback was that this was too many to provide a satisfactory level of patient care and student supervision.

From the point of view of the dental school, an important element of clinical training was transferred from the dental hospital to community-based clinics. Not all dental school staff supported this move and some saw it as potentially detrimental to quality. The academics involved in the external evaluation however considered that the students had been able to maintain a high quality of service while developing their productivity. They recognised the need to give new outreach teachers opportunities to spend time at the dental school prior to working in outreach, to provide training in student assessment, and to establishing links between academic staff and clinic colleagues to facilitate student monitoring and identification of problems.

\section{Changing outreach as a context \\ for teaching}

In order to address problems identified through the action research, changes affecting teaching were introduced throughout the pilot. These included longer induction for students with written information covering cross-infection control, note writing, time management and professional attitude; a revised grading system as part of a dental schoolwide initiative; a review of the guidance on course requirements; a revised seminar programme to introduce more relevant topics such as patient management; and protocols for the transfer of patients between outreach and the dental hospital. Regular meetings for the teaching staff only were established to provide mutual support and exchange of information. After the pilot, when the course became part of the mainstream undergraduate programme, changes to the management structure of the dental school meant that a single course co-ordinator became responsible for the teaching of all restorative dentistry both within the dental school and in outreach. Further developments included away days for all clinic staff, an improved system for providing a specialist opinion, the ending of course requirements, and the elimination of seminars in the clinics.

In terms of longer term planning, to provide a more supportive environment a decision was made to make joint PCT/university appointments for teaching staff in the future, with the PCT as the employer, and posts have been created. It was also decided that any future 


\begin{tabular}{|c|c|}
\hline Personal qualities & $\begin{array}{l}\text { Approachable } \\
\text { Authoritative } \\
\text { Calm/relaxed/patient } \\
\text { Consistent } \\
\text { Committed } \\
\text { Encouraging } \\
\text { Flexible } \\
\text { Friendly } \\
\text { Helpful } \\
\text { Sense of humour } \\
\text { Tactful } \\
\text { Thick skin }\end{array}$ \\
\hline Abilities & $\begin{array}{l}\text { Able to cope with stress } \\
\text { Able to cope if things go wrong } \\
\text { In control/in charge } \\
\text { Able to relinquish control }\end{array}$ \\
\hline Skills & $\begin{array}{l}\text { Good communicator } \\
\text { Good time management } \\
\text { Well organised/plans ahead } \\
\text { Team player } \\
\text { Able to delegate to/listen to nurses } \\
\text { Teaching skills } \\
\text { Good clinical skills } \\
\text { High standard of patient care } \\
\text { Consideration for/understanding of patients }\end{array}$ \\
\hline Teaching & $\begin{array}{l}\text { Recognise/adjust to students' individual skill/needs } \\
\text { Able to win respect of students } \\
\text { Respectful of students } \\
\text { Supports/checks student work as necessary } \\
\text { Available to take over if necessary } \\
\text { Grades realistically/with explanation } \\
\text { Honest with students } \\
\text { Able to discipline when necessary } \\
\text { Distributes time fairly } \\
\text { Provide concise explanations and clear direction and guidance so } \\
\text { students know what expected of them and why }\end{array}$ \\
\hline Knowledge & $\begin{array}{l}\text { A generalist } \\
\text { Up to date knowledge of techniques in restorative dentistry } \\
\text { Able to work in accordance with academic standards }\end{array}$ \\
\hline
\end{tabular}

developments would be based on the supervision of four surgeries per teacher as the maximum for appropriate teaching and patient care.

\section{DISCUSSION}

The evaluation reported here is based on the experience of a single outreach scheme with particular organisational features. While the findings are specific to that scheme, they also point to the more general issues that those organising outreach need to consider.

Most British studies of outreach tend to focus on the effect on students, which are usually positive..$^{2,17-19}$ Consistent with this view, the pilot considered here demonstrated that in general the students valued the experience and skills they gained from outreach. ${ }^{9}$ A British study of staff perspectives on student outreach placements $^{20}$ identified positive attitudes towards outreach, which was seen as providing productive teaching and learning experiences. In the evaluation presented here both the outreach teachers and dental school academics thought outreach benefited students in a variety of ways. From the managerial perspective, the PCTs involved were enabled to provide a new accessible local service valued by patients. ${ }^{11}$ However this paper has also highlighted some of the more problematic areas related to outreach as a context for teaching.

Outreach represented a more demanding environment in which to teach than the dental hospital. The teachers found teaching in isolation stressful as they had no-one to turn to for immediate advice and support. At the same time they carried the additional responsibility of managing the clinic, and, in the early stages, of learning a new role. The characteristics identified as desirable in an outreach teacher tended to emphasise the personal qualities, abilities and skills necessary to cope successfully in this environment, together with a student-centred teaching style and the appropriate knowledge. The results of this study should alert those planning outreach teaching schemes to ensure adequate training of supervising clinicians and to offer ongoing practical support. In the paediatric outreach course in Manchester, students are given one to one chairside assistance by nurses. In the restorative outreach pilot described here, such an arrangement, rather than student pairing, may have reduced the supervisory burden on the teachers.

Christie, Freed and Marcus ${ }^{21}$ note the tensions between the competing needs of educational requirements, access to dental care, financial viability and service to the community that has to be managed in the outreach environment. In the pilot considered here an important element of undergraduate clinical training was transferred from the dental hospital to the community. For the dental school this meant that teaching became at arm's length, with implications for ensuring consistency, quality, and effective communication with the teachers and the PCTs. American experience suggests that in relation to quality, community-based programmes can be at least as effective as school-based experiences in providing students with a sound clinical education..$^{22}$ Smith et al. ${ }^{20}$ note that effective communication and adequate resourcing are critical success factors. Other dental schools have adopted different models of outreach. Bailit ${ }^{23}$ recommends further research to evaluate different systems with a view to improving organisation and operation.

The general consensus for the model considered here was that four students was the safe maximum that could be adequately supervised by one outreach teacher. As a result small outreach clinics with individual surgeries will be a more expensive option than either the traditional open-plan dental school clinic or physically large outreach schemes. The latter may be more cost effective but reduce the primary care attributes of 
outreach, whereby the students feel part of a team and get to know their teacher and local community.

In developing the new arrangements, the PCTs were key partners. The pilot demonstrated the importance of working closely with them and of recognising the implications for them of the transfer of management responsibilities, in terms of the workload generated by staff issues, risk management and service-related factors. The pilot also showed the value of monitoring and feedback in identifying and dealing with difficulties, both academic and organisational, as they arose.

In developing outreach facilities to enable students to benefit from the many advantages of outreach teaching, it is important for dental schools to recognise that the particular characteristics of outreach as an environment for teaching have to be taken into account in the planning process, that staff selection is a critical success factor, and that an ongoing proactive approach to organisational arrangements and to the support of teaching staff is necessary.

The pilot project was originally funded by the National Purchasing Unit for Dental SIFT and the North West Regional Office of the NHS Executive, and subsequently by their successor organisations, the National Dental Development Unit and Greater Manchester Workforce Development Confederation/Strategic Health Authority, together with the University Dental Hospital of Manchester. The evaluation was funded in part by LTSN-01. Thanks are due to members of the Development Team and Evaluation Working Party, as well as to the students and clinic, management and academic staff who contributed to the evaluation.

1. Department of Health. NHS dentistry: options for change. London: Department of Health, 2002

2. Holloway P, Dixon P. Extra-mural experience for undergraduate dental students. Br Dent J 1977; 143: 146-150.

3. Chapnick $L$, Chapnick $A$. Clinical undergraduate teaching. J Endod 1999; 25: 686-688.

4. Harden R, Crosby J. AMEE Guide No 20: The good teacher is more than a good lecturer - the twelve roles of the teacher. Medical Teacher 2000; 22: 334-347.

5. Fugill M. Teaching and learning in dental student clinical practice. Eur J Dent Educ 2005; 9: 131-136.

6. Chambers D W, Geissenberger M, Leknius C. Association amongst factors thought to be important by instructors in dental education and perceived effectiveness of these instructors by students. Eur J Dent Educ 2004; 8: 147-151.

7. Elkind A. Outreach teaching: is this the future for dental education? Br Dent J 2002; 193: 111-112.

8. Ovretveit J. Evaluating health interventions: an introduction to evaluation of health treatments, services, policies and organisational interventions. Buckingham: Open University Press, 1997.

9. Elkind A, Blinkhorn A, Blinkhorn F et al. Developing dental education in primary care: the student perspective. Br Dent J 2005; 198: 233-237.

10. Elkind A, Potter $C$, Watts $C$ et al. Patients treated by dental students in outreach: the first year of a pilot project. Eur J Dent Educ 2005; 9: 49-52.

11. Elkind $A, B$ linkhorn $F$, Mackie I et al. Service quality implications of dental undergraduate outreach teaching for primary care trusts in England, UK. Community Dent Health 2006; 23: 75-79.

12. Iles V, Sutherland K. Managing change in the NHS: organisational change, a review for health care managers, professionals and researchers. National Co-ordinating Centre for NHS Service Delivery and Organisation Research and Development, 2001.

13. Wilkinson E, Elander E, Woolaway M. Exploring the use of action research to stimulate and evaluate workplace health promotion. Health Educ J 1997; 56: 188-198.

14. Phillips C, Palrey C, Thomas P. Evaluating health and social care. London: Macmillan, 1994

15. Taylor I, Turner R. An external evaluation of a pilot outreach course in restorative dentistry at the University Dental Hospital of Manchester. Liverpool Evaluation Unit, University of Liverpool, 2003.

16. Elkind $A, B$ linkhorn $A$, Watts $C$ et al. Developing dental education in primary care: report of the first year of a pilot outreach course in restorative dentistry. University Dental Hospital of Manchester, 2003.

17. Barnes J. The Health Centre Programme. The School of Dentistry, the University of Liverpool. Report No 3: The perceptions of recently qualified dental surgeons and dental therapists. Liverpool Evaluation and Assessment Unit, Department of Education. The University of Liverpool, 1999.

18. Blinkhorn F. Evaluation of an undergraduate community-based course in family dentistry. Eur J Dent Educ 2002; 6: 40-44.

19. Lennon M, Ireland R, Tappin J et al. The personal dental service as a setting for an undergraduate clinical programme. Br Dent J 2004; 196: 419-422.

20. Smith M, Lennon M, Brook A et al. Perspectives of staff on student outreach placements. Eur J Dent Educ 2006; 10: 44-51.

21. Christie D, Maida C. Freed J et al. Identifying and responding to competing needs: a case study of a dental school-operated community clinic. J Dent Educ 2003; 67: 1243-1251.

22. DeCastro J, Bolger D, Feldman C. Clinical competence of graduates of community-based and traditional curricula. J Dent Educ 2005: 69: 1324-1331.

23. Bailit H. Community-based clinical education programs. Major findings and recommendations. J Dent Educ 1999; 63: 981-989. 